\title{
5. International human resource management in multinational corporations from emerging economies
}

\author{
Mohan Thite
}

\section{INTRODUCTION}

Global challengers are on the hinge of history, balanced between a remarkable past decade of growth and innovation and promising but unproven future. (BCG, 2011)

The literature on multinational corporations (MNCs) has so far concentrated heavily on MNCs from Western countries entering other advanced economies and/or developing economies (OECD, 2006). This is not surprising considering that until recently the international business was dominated by Western MNCs. While this is still the case, the emerging economies are causing structural changes in the global economic landscape with substantial economic growth now occurring in these economies. While it is clear that the domestic markets in the emerging economies are the future engines of growth as reflected in the inflow of foreign direct investment (FDI), what is less noticeable is that the emerging economies are also increasingly contributing more towards outward FDI and interestingly they are investing both in developed as well as developing markets, that is both South-North and South-South investment (Ramamurti and Singh, 2009). Correspondingly, the number of MNCs from emerging economies (hereafter referred to as EMNCs) is also on the increase.

In 2011, not only that 8 out of the top 10 destinations for foreign direct investment (FDI) were from the developing and transition economies, they also accounted for 30 per cent of global outward FDI flows (UNCTAD, 2012). In 2006, they conducted over 1,000 mergers and acquisitions (M\&As), worth $\$ 128$ billion (UNCTAD, 2007). The EMNCs from the developing countries are estimated to be now over 21,000 of which about 3,500 were from China, 1,000 from Russia, 815 from India and 220 from Brazil (UNCTAD, 2009). The share of EMNCs in the Fortune Global 500 list has gone up from 21 to 75 over the last decade. 
It is anticipated that over 70 per cent of the world's growth in the next few years will come from emerging markets (Economist, 2010).

Luo and Tung (2007, p. 4) define EMNCs as 'international companies that originated from emerging markets and are engaged in outward foreign direct investment where they exercise control and undertake value-adding activities in one or more foreign countries'. Some of the common features of EMNCs in terms of their reasons for, approach to and competitive advantages in their internationalization are:

- a high degree of adaptability and flexibility in overcoming uncertainties in the external environment (Gulliéan and Garcia-Canal, 2009);

- ability to overcome 'institutional voids' and turning adversity into an opportunity by developing 'bottom of the pyramid' products and services tailored for the domestic market and similar overseas markets (Khanna and Palepu, 2005);

- they pursue a 'springboard strategy' of simultaneous entry into developed and developing country markets in order to exploit their home-grown advantages in other similar markets and at the same time seek intangible resources in advanced markets (Luo and Tung, 2007);

- their entry mode is mainly via global alliances and acquisitions in contrast to greenfield ventures to overcome the liability of foreignness and country of origin (Sun et al., 2012);

- their speed of internationalization is rapid rather than gradual (Deng, 2012); and

- they rely more on social networks and government support and operate more in mature technologies (Gammeltoft et al., 2010).

The increasing number and stature of EMNCs is in many ways a challenge to the conventional theories of multinational enterprise. While MNCs from Japan and Asian Tiger economies (Hong Kong, Singapore, Taiwan and South Korea) have been around for quite some time, it is still the case that the theories of MNC are primarily looked at from the prism of Western MNCs. For example, contrary to the OLI (ownership, location and internalization) framework, EMNCs rarely possess monopolistic ownership advantages (Goldstein, 2009) and as is the case with many Indian MNCs, EMNCs may internationalize as a de-risking strategy to overcome constraints in expanding in their domestic markets. Here, the resource-based perspective and Mathews' (2006) 'linkage, leverage, learning' (LLL) framework are more useful in explaining the phenomenon of EMNCs, particularly, in the context of human resource management (HRM). 
Considering the heterogeneity amongst EMNCs in terms other geographical dispersion (Asia, Central and Eastern Europe, the Commonwealth of Independent States, the Middle East, Latin America and Africa), cultural, political, economic, religious and institutional differences and their approach to, speed and scale of internationalization and HR strategies and practices, this chapter limits itself to the BRICS region as it is considered the most visible, prominent and promising block amongst the emerging economies (Fleury and Fleury, 2011). For instance, the Boston Consulting Group's report (BCG, 2011) on the 100 global challengers from rapidly developing economies is dominated by BRICS countries with 33 Chinese MNCs, 20 Indian MNCs, 14 Brazilian MNCs, 6 Russian MNCs and 5 South African MNCs.

The purpose of this chapter is to trace the growing global footprints of the multinationals from emerging economies in the BRICS block, from both theoretical and empirical perspectives, in order to understand their motives, strategies and constraints for internationalization, particularly from the human resource management perspective. It starts its enquiry by looking at the research questions, directions and inferences on the EMNCs, first from the international business/management discipline perspective, followed by the HRM perspective. It then focuses on the limited number of empirical research studies on the evolution, management and prospects of international HRM in EMNCs in each of the BRICS countries as well as comparative research between them. Finally, it brings the theoretical and research insights together to find convergence, divergence and cross-vergence in the international HR strategies, policies and practices in EMNCs and identifies future research directions to further enrich the growing but as yet nascent understanding of, what Boston Consulting Group calls the global challengers.

\section{INTERNATIONAL MANAGEMENT AND EMERGING MARKET MULTINATIONALS: RESEARCH DIRECTIONS}

The question as to why firms internationalize has been addressed by several disciplines in social sciences, such as economics, management and sociology, but each focus on parts rather than the whole. Further, they have so far focused their attention mainly on MNCs from Western/ developed economies and therefore, their relevance to the emerging markets MNCs needs to be carefully scrutinized.

One of the most dominating Anglo-American theories on MNCs is the 'eclectic theory' of ownership, location and internalization (OLI) which 
highlights on the ownership related firm-specific advantages (why), location related country-specific advantages (where) and organizational structure related internalization advantages (how). The OLI theory fails to explain why and how the internationalization of EMNCs is very rapid and different from that of the conventional Western MNCs and erstwhile developing country MNCs (Matthews and Zander, 2007). Goldstein (2009) argues that in the context of EMNCs, they rarely possess monopolistic advantages and the OLI model is static as it neglects situational and personality contingencies surrounding the decision making process.

In the contemporary global market, firms are continually required to learn new business approaches and strategic orientations and accordingly, Mathews (2006) proposes that the internationalization of modern MNCs, particularly the EMNCs, is driven by resource 'linkage, leverage and learning' (LLL) as opposed to the traditional OLI framework. Mathews argues that unlike established MNCs which seek to exploit their existing competitive advantages to internationalize, the EMNCs internationalize in order to gain new competitive advantages by acquiring intangible resources (such as technology, brand power and management expertise) that would otherwise be unavailable to them.

The resource-based view (RBV) is another critical theory on the MNCs which takes an inside-out look at the dynamic capabilities of firms in optimally bundling internal resources that are rare, valuable and difficult to imitate (Barney et al., 2011). For example, intra-firm knowledge generation and the flow of knowledge across the global network is one such dynamic capability. The resource-based view offers rich possibilities in explaining the competitive advantages of EMNCs which are renowned for overcoming adversity (Cuervo-Cazurra and Genc, 2008), late mover disadvantage into an advantage (Bartlett and Ghoshal, 2000) and possessing a high degree of adaptability and flexibility (Gullién and Garcia-Canal, 2009). Luo and Rui (2009) offer a new theoretical lens in the form of an 'ambidexterity perspective' of EMNCs to explain how they seek to simultaneously achieve alignment between short-term survival and long-term growth (co-orientation), transactional and relational capabilities (co-competence), competition and cooperation with stakeholders (co-opetition) and both influence and respond to external environment (co-evolution). Similarly, Chen and Miller (2010, 2011) argue that EMNCs typically follow an 'ambicultural' mode of management that avoids dangerous extremes of transactional and relational perspectives. Thus, the LLL framework and the resource-based view together seem to provide a powerful explanation of the rapid rise of EMNCs (Goldstein, 2009). 
The international business/management strategy research has recently sharpened its focus on EMNCs \&(Wright et al., 2005); however, many key research questions are yet to be seriously addressed. For example, we know very little on how EMNCs respond to the dual pressures to conform to home country (push force) and host country (pull force) institutional environments.

The country of origin is widely considered to have a major impact on the coordination of control of subsidiaries in the MNCs, particularly in balancing between the need for global integration and local adaptation (Harzing and Sorge, 2003). In the context of EMNCs, the liability of foreignness is further compounded by the liability of country of origin with perceived poor global image of their home country. Further, they are not only relatively small in size but are also in their early stage of internationalization with limited international experience (Contractor et al., 2007). They also have to deal with the liability and competitive disadvantage that stems from being late-comers, lacking the resources and capabilities of established MNCs (Guillén and Garcia-Canal, 2009). It is worth finding out whether and how organizational culture, decision making and control on subsidiaries in EMNCs are different from established MNCs due to differences in national culture, economic development and lack of experience as global players. Also, considering that a significant number of EMNCs are state-owned or family enterprises, future research needs to shed light on how they develop dynamic capabilities in the competitive global marketplace (Dixon et al., 2010).

\section{HRM IN EMERGING MARKET MULTINATIONALS: THEORETICAL PERSPECTIVES}

Closely aligned with the organizational learning perspective as highlighted in the LLL framework proposed by Mathews (2006) are the knowledge management and learning organization perspectives and how human resource management discipline can drive the knowledge management process in order that an MNC becomes a true learning organization at a global level. Thite (2004) highlights how knowledge management as a goal and learning organization as a means can help to strategically position the HR discipline. In the context of an MNC, the corporate/ global HR plays a vital role in generating and disseminating both explicit and tacit knowledge across the entire global network (Sparrow et al., 2003). This role becomes even more important in an EMNC as it tries to catch up with established MNCs through its operations and acquisitions in developed markets (Dixon et al., 2010). Some of the key enablers in 


\section{Handbook of HRM in emerging markets}

HR successfully performing this role are the experience of subsidiary HR managers, their relationship with corporate HR managers (Makela et al., 2012) and the ability as well as motivation (absorptive capacity) of employees in subsidiaries for knowledge transfer (Minbaeva et al., 2003).

While the general international HRM (IHRM) literature has dealt extensively with the relevance of Western-based HRM theories and practices to non-Western countries, there is a growing demand to develop alternate models that expressly recognize and incorporate indigenous HR systems in studying HRM in MNCs from emerging economies (Jackson, 2001). For instance, Horwitz (2012) proposes an Afro-Asian nexus in South African MNCs based on the common cultural traits between African countries, China and East Asia, mainly around family orientation and collective solidarity. Similarly, in the context of Chinese multinationals operating in Vietnam, Cooke and Lin (2012) argue that

the role of institutional actors differs across ownership forms and industrial sectors and that a multi-theoretical perspective, including in particular the political economy perspective, is needed to study Chinese MNCs' HRM practices in order to more fully understand how the practices are shaped and perceived. (Cooke and Lin, 2012, p. 205)

In the same vein, Chatterjee and Pearson (2001, p. 81) provide evidence to show that Indian managers are combining traditional values and dimensions of contemporary global market imperatives in a unique way. Cappelli et al. (2010a) contrast the American management style with that of major Indian firms and show how they achieve business success by putting social mission ahead of shareholder value through 'extraordinary investments in their employees and empower them in decision making'. They take 'long-term, internally focused view', treat corporate social responsibility (CSR) as a reputational asset with 'social mission and a sense of national purpose', engage employees through transparency and accountability and invest heavily in employee training (Cappelli et al., 2010b).

Zheng (2013) critiques that the existing IHRM models are inadequate in their application to emerging market multinationals for a number of reasons, including that their motives for internationalization are quite different than those of established MNCs, that their institutional environments, both in home and host countries, are constantly changing and evolving, that their national and corporate cultures are more complex and that they need to focus on different internationalization outcomes beyond firm performance to include community development. 
Despite some of the research advances outlined above, the international HRM discipline is yet to adequately respond to the growing importance of EMNCs, even though it readily acknowledges the importance of situational contingencies to strategic HRM (Lengnick-Hall et al., 2009) and the changing nature of global economic landscape (Scullion et al., 2007). For instance, the national culture has been highlighted as a major differentiating factor between differences in HRM (Hofstede, 2007) even though this has been recently called into question (Gerhart and Fang, 2005). We do not know enough about how cultural and institutional differences affect the dissemination of HRM strategies and practices by MNCs from emerging economies operating in a developed and/or developing economy (Chang et al., 2007).

The following section provides some preliminary evidence from recent studies addressing some of these key research questions. The EMNCs are very heterogeneous as they come from different countries and industries and target different markets with different entry strategies and firmspecific advantages making it extremely difficult to generalize their features (Ramamurti, 2009), particularly in the context of HRM (Horwitz and Mellahi, 2009). Therefore, as stated before, for practical purposes, the following section limits itself to the BRICS countries.

\section{HRM IN EMERGING MARKET MULTINATIONALS: PRACTICE PERSPECTIVES FROM BRICS}

Considering that the EMNCs are a very recent phenomenon and are still in an infancy stage, it is not surprising that the research and literature on their HR strategies and practices are quite limited (Zheng and Lamond, 2009). The following description of HRM in MNCs from BRICS is an exploratory account of the current state of knowledge which is later used for the purpose of broad discussion and identification of future research directions.

Before we look at the individual countries, it is important to note the important contextual factors, both external and firm-specific factors, affecting the development of an IHRM model for EMNCs. Table 5.1 provides a list of such factors as identified in studies focusing on HRM in EMNCs. 
104 Handbook of HRM in emerging markets

\title{
Table 5.1 Contextual factors affecting IHRM in EMNCs
}

\author{
Shen et al. External: Political, economic, legal, sociocultural factors. \\ Internal: International strategy, organizational structure, \\ organizational culture, stage and mode of internationalization, type \\ and niche of industry, international experience, size of international \\ operation, the reliance on international markets, top management \\ perceptions of home HRM systems.
}

Thite et al. External: Home Country Factors (economic strength; global image; national culture etc.); Host Country Factors (perceived relative strength of home and host country management practices; Environmental Factors (openness of business systems, legal framework, institutions etc.); Industry-specific Factors (degree of product integration; level of integration between headquarters and subsidiaries etc.).

Internal: Strategic framework (business, corporate, international, cooperative); Organizational culture/leadership; Importance of subsidiaries to MNCs bottom line and strategy; Mode of subsidiary set-up (greenfield, M\&A ... ); Headquarters' diffusion capacity; Subsidiaries' absorptive capacity; Subsidiaries' resource dependency on the headquarters; Availability, ability and choice of expatriate managers.

Thite et al. External: Country of origin.

(2014)

Internal: Corporate Strategy (international, multi-domestic, global, transnational); IHRM Strategy (adaptive, exportive, integrative);

Business Structure (holding company, allied/diversified organization, single/functional business); IHRM Structure (dependent, interdependent and independent); CEO Perceptions (scope for CEO action, willingness to delegate responsibility, aptitude of the HR department); Miscellaneous (size of its global workforce, standardization of its products or services along with the regional/ global basis, use of a global HR policy formation body, governance mechanism, characteristics of the subsidiary HR systems, the social relationship between the subsidiary and the headquarters, the transfer approach taken by headquarters management).

Wocke et al. External: National culture.

(2007)

Internal: MNC business model, type and role of organizational culture in managing affiliates.

\section{Brazilian Multinationals}

It is estimated that in 2010 , there were more than 80 Brazilian multinationals, mainly in banking and resources sectors, and six of them were counted amongst the Fortune 500 (Fleury and Fleury, 2011, p. 36). The 
economic liberalization in early 1990s was the trigger for the internationalization of Brazilian firms. The organizational culture in many Brazilian firms was heavily influenced by the Japanese quality management techniques and many government initiatives accelerated the process of national quality and productivity improvement (ibid, p. 176). This helped the transformation of the "traditional Brazilian management style' to suit the modern, competitive global environment but without losing local cultural connections rooted in collectivist traditions (ibid, pp. 178-179).

According to a survey conducted by Fleury and Fleury (2011, p. 211213), the senior managers in Brazilian MNCs rated HRM as the least important of the nine organizational competencies to compete domestically but the third most important to enter an international market, after production and organizing. The task of transferring key personnel from headquarters to overseas operations to integrate the international unit during the entry phase was seen to be a key competence. However, during the international expansion and consolidation phase, HRM was relegated to eighth important competence. Interestingly, the managers in the overseas subsidiaries felt that their HRM competence was superior to that of the headquarters, probably because of the strong local content (p. 218). The authors conclude that for Brazilian multinationals, 'for historical and institutional reasons, the most critical but evidently weak competence is HRM' (Fleury and Fleury 2011, p. 222).

For Brazilian MNCs, market opportunity was a more important consideration than cultural proximity in choosing which country to enter into; however, they uniformly stressed the critical importance of solid groundwork to deal with cultural differences, such as language barriers, political and economic differences (Muritiba et al., 2010). In their quest for internationalization, Brazilian multinationals find that 'shortage of qualified workforce to work internationally and the need to develop HRM competencies to operate globally' as some of the key challenges (Muritiba et al., 2012, p. 248). According to Tanure et al. (2009) Brazilian expatriates, who are predominantly sent to countries that are culturally distant to theirs, cited cultural integration as the biggest challenge; yet, Brazilian multinationals did not seem to incorporate this perception in the expatriation selection and training process. Another study of Brazilian technology multinationals found that their HR strategies were more localized than internationalized and that the subsidiaries lacked autonomy in driving their HR strategies as decision making was concentrated in headquarters (Muritiba et al., 2010). These studies together support the conclusion reached by Fleury and Fleury (2011) that HRM seems to be the weakest link for Brazilian multinationals. 


\section{Russian Multinationals}

Russia's competitive advantage mainly stems from its natural resources and with the disintegration of the Soviet Union, 'oligarchic capitalism' prevails in Russia as few oligarchs maintain tight control over the natural resources and spearhead Russia's internationalization drive, with the active backing of the government (McCarthy et al., 2009, p. 382). There are around 60 Russian multinationals, essentially in the natural resources sector, seeking economies of scale with vertical downstream integration by acquiring resource-rich companies overseas, mainly in Western and Central Europe and Commonwealth of Independent States (CIS) (Fleury and Fleury, 2011, p. 383). Geographical proximity and cultural-historical closeness are important considerations in the internationalization of Russian multinationals apart from resource-seeking, market-seeking and efficiency-seeking motives (Kuznetsov, 2012).

A key feature of Russian culture is that 'trust and personal relationships are highly valued, and hierarchy is respected' and employee empowerment is rarely practiced (Filippov, 2012, p. 330). While Russian multinationals still remain 'predominantly Russian', as they expand overseas, they are forced to modernize their management practices to suit the markets in which they operate. Accordingly, they are expected to move away from 'purely hierarchical structures, and empowering and motivating their workforce' and in the process, they try to seek a 'delicate balance - 'just enough for the west and not too much for Russia' but over time, this transformation is expected to percolate down to their home country operations as well (Filippov, 2012, p. 336).

Even though Russia inherits a rich tradition of technical and scientific advancement, education and personnel from the Soviet era, it has largely lagged behind in converting that knowledge into innovation (Narula and Jormanainen, 2008). In this context, Filippov (2011) observes that

Russia produces an educated workforce that could be ready for innovation but has so far been unable to establish the institutional framework to benefit from the investments in education and science. (Filippov, 2011, p. 189)

To mitigate the same, just as other emerging market multinationals, some Russian multinationals have started seeking and acquiring technologyintensive assets in Western countries, even though the motivation to innovate is lower for those in the resources sector. In analyzing the implications of lack of innovative mindset and culture on HRM, Filippov (2011) states: 
[to foster organizational learning] Companies should develop an open mind towards innovation. The employees need to have the learning skills to absorb new information and technology, especially if it comes from an acquired foreign company or results from collaborative efforts. It may require setting up tailored training programmes for staff members, learning a foreign language (English), understanding standards of a different context. In many Russian organizations the basis of innovation, risk taking, embracing failure, and reward for action, are not supported. (Filippov, 2011, p. 203)

\section{Indian Multinationals}

The internationalization of Indian firms is typically described in two phases:

- Pre-1991, when the socialist-oriented government policies severely restricted the growth of the private sector (both at home and abroad but allowed limited expansion into neighbouring countries) and also stifled innovation by killing foreign competition in the domestic market; and

- Post-1991 when market liberalization, forced by dire economic circumstances, finally allowed foreign firms to enter India forcing and at the same time motivating domestic firms to innovate and grow globally (Kumar, 2007; Ramamurti and Singh, 2009).

Prior to 1991, large family owned Indian business conglomerates, such as Tata and Birla, set up greenfield operations mainly in South East Asia leveraging their expertise in cost-effective utilization of second-hand foreign technologies in manufacturing operations. However, the second wave of international expansion unleashed the entrepreneurial spirit of Indian enterprises, large and small, private and government owned and manufacturing and services as evidenced in more than 800 per cent growth in outward foreign direct investment between 1991 and 2003 (Pradhan, 2007). Their preferred mode of international entry strategy is acquisitions, mainly in developed markets, seeking new technologies, skills and expertise. Today, Indian multinationals are mainly privately owned and operate in highly competitive service sectors, such as information technology (IT) services, including back office operations (UNCTAD, 2006). They are well-known for their highly cost-effective operations; skilled manpower (that is abundant, though not necessarily fully employable, relatively cheap, young, well-educated in English and culturally highly adaptable); reverse engineering skills and global delivery expertise in offshored services (Thite and Dasgupta, 2011; Jonsson, 2008). 
By interviewing the global heads of HR in a diverse range of Indian multinationals, Thite (2014) traced the evolution of HRM to become a strategic corporate player, shift towards performance-centric organizational culture, striving but still struggling to create a truly diverse global workforce with a global mindset, weaning away from India-centric centralized decision making process and developing a global leadership pipeline to maintain and consolidate international growth. Based on the case studies of four Indian IT services MNCs, Thite et al. (2014) identified five key global HR roles in these firms, namely, strategic business partner, guardian of culture, builder of global workforce and capabilities, champion of processes, and facilitator of employee development. Their analysis also highlighted that the HR function in Indian IT services MNCs faced several challenges in consolidating the early gains of internationalization, such as lack of decentralized decision making, developing a global mindset, localization of workforce and developing a global leadership pipeline.

In other studies on HRM in Indian multinationals, one provided preliminary evidence on how an Indian multinational conglomerate mixed and matched indigenous business and people management strategies with the Western emphasis on meritocracy and professionalism to successfully compete in the contemporary global economy (Thite, 2013, Som, 2010) and another identified diffused and empowered leadership, metrics and value driven performance and reward management and strategic mindset of the HR function as the key ingredients of success in an Indian IT multinational (Thite, 2012).

Thite et al. (2012) found that like other EMNCs, Indian multinationals faced multiple hurdles in furthering their internationalization strategies, including recruiting local talent at their overseas operations due to poor perception of their employer brand, which in turn restricted their ability to localize their global workforce. They followed an 'adaptive approach' in managing subsidiaries in developed markets, reinforcing their desire to learn and adopt world's best management practices. However, rather than following an ethnocentric or exportive approach to managing subsidiaries in other developing markets, as is generally described in the literature on Western MNCs, the Indian multinationals adopted a 'highly localized' approach, as they did not know much about emerging markets and therefore, preferred empowering local managers to run the operations with only broad corporate oversight. 


\section{Chinese Multinationals}

As with other EMNCs, the main motivation for Chinese multinationals to internationalize is to acquire strategic assets to bolster their competitive advantage (Parmentola, 2011). The preferred mode of international expansion for Chinese MNCs is acquisition as it helps them to secure natural resources and rapidly scale up as global players by acquiring foreign technology and know-how (Goldstein, 2009).

Teagarden and Cai $(2009$, p. 76) trace the HRM issues that Chinese multinationals face during various phases of their international expansion as below:

- Learning Phase: Build vision and values, Establish corporate culture, Build manufacturing skill sets

- Build-Up Phase: Build professional management skill sets, Formalize HRM practices

- Internationalization Phase: Harness local talent, Build expatriate management, Build high-performing work systems, Build crosscultural capabilities

- Globalization Phase: Build mindshare, Build localization abilities with global integration

- Global Dominance Phase: Build global mindset, Build global social controls.

Shen et al. (2005) highlight the dilemma in the minds of decision makers in Chinese MNCs with regard to convergence and divergence of HR practices in their global operations in that on the one hand, they realize that their home country HRM systems are untransferable because they are only applicable in the unique context of the Chinese economic, political and social system but on the other hand, they don't want to give total freedom to subsidiaries to adopt local practices for fear of losing control (Shen et al. 2005, p. 383). Also, they tend to adopt ethnocentric staffing approach in the initial phases of internationalization because of their inability to attract top talent in the host countries and also the reluctance to provide training and development opportunities for host country nationals (p. 385).

Shen and Edwards' (2006) study of international HRM (IHRM) practices in Chinese MNCs revealed that:

- They adopt an integrative approach to IHRM with a simultaneous consideration of integration and adaptation to HR practices. 
- They are 'relatively centralized in recruitment and selection, management and reward and compensation, but decentralized in training, performance appraisals and employee relations' (pp. 156-157).

Reiterating their adaptive/integrative approach to IHRM, Edwards and Zhang (2003) provide evidence that six Chinese multinationals adopted local HR practices in their subsidiaries in the UK and this preference for localization stemmed from their desire to adhere to local cultural and regulatory norms as well as to learn advanced management techniques in their quest to become global players.

After reviewing the HR policies of three high-profile Chinese MNCs which were formerly state owned enterprises, Warner and Nankervis (2012) conclude that they have well-articulated mission and business strategies that have helped shape their HRM architectures, their HR practices exhibit several features of strategic HRM as advocated in the West; however, the rhetoric of these features are sometimes at odds with the reality of their implementation on the ground.

Cooke and Lin (2012) neatly summarize the state of HRM in Chinese MNCs as below:

Chinese MNCs are heterogeneous in their scale, business nature, corporate competence, market opportunity and level of institutional support. They range from large state-owned firms which are going global with a political task to fulfill to small private firms driven by opportunity rent-seeking and short-term behavior of their owners ill-equipped for international operations. These factors underpin their labor/HRM strategies that lead to diverse employment outcomes for those employed by the Chinese MNC subsidiaries. (Cooke and Lin, 2012, p. 221)

In terms of future challenges, Teagarden and Cai (2009) note that Chinese multinationals 'must all continue to build their leadership pipelines, embrace succession planning, and master talent management in multiple labor markets, not just at home' (p. 79). Cooke (2008) makes similar observations:

In general, Chinese managers still lacks (sic) foreign market knowledge, experience and international expertise. They also have insufficient understanding of host countries' employment legislation and characteristics of labour relations, particularly the different attitudes towards trade unionism. Chinese firms further suffer from an image stereotyping in developed countries where they may be seen as inferior. (Cooke, 2008, p. 259) 


\section{South African Multinationals}

In recent times, the African continent has taken a leap forward towards economic progress, with countries such as South Africa (SA), Ghana, Angola and Nigeria leading the charge (The Times, 2011). As a recent entrant to BRICS block, South Africa has had a highly differentiated institutional context having only recently come out of apartheid regime and still reeling from racial tensions. Natural resources are its biggest national competitive advantage and the firm-specific advantages come mainly from the ability of South African firms to deal with domestic turmoil and upheaval to act as a protective incubator against external economic sanctions in the 1970s and 1980s (Klien and Wocke, 2009). As such, the South African firms have seen rapid reorganization of the conglomerates and strong ties with the European business community (Goldstein and Prichard, 2009).

A study of four SA MNCs by Wocke et al. (2007) found a considerable degree of variance in corporate HR strategies due to differences in business model, the need to accommodate national culture, the type and role of organizational culture. This variance in turn influenced their ability to converge with international HR best practices. They also found that the more the cultural distance between the home and host countries, the more the divergence in HR practices. Another study found that according to the HR practitioners in SA MNCs, performance improvement, employment equity, training and development and managing trade union expectations were the most important workplace challenges (Grzeschke and Moehring, 2004).

Considering that a significant number of Asian MNCs, particularly from China and India, are currently operating in South Africa, Horwitz (2012) identifies an Afro-Asian nexus in tracing the evolution of HR function and practices in South African MNCs, in line with Jackson's (2001) humanistic versus the instrumentalist locus of values towards employees between the East and the West. Some of the common cultural traits that Horwitz highlights between African, Chinese and East Asian cultures are focus on internal stakeholders, collective solidarity, consultative and participative decision making and extended family orientations. This nexus explores how the HRM practice in the African continent is converging on East Asian firms but with its own distinct indigenous thought systems and contextual factors. This has led to cross-vergence or hybrid models of HR policy and practice. 


\section{Handbook of HRM in emerging markets}

\section{Comparative Research}

Considering the growing South-South investment flows between the emerging economies, it is important to study how the MNCs from emerging economies find the experience of operating in each other's countries but there is very little research on this front (Cuervo-Cazurra and Genc, 2008). It is even more limited in the context of HRM.

Akorsu and Cooke (2011) examined the impact of Chinese and Indian investments on the employment conditions in Ghana and concluded that the weaknesses in the institutional and financial capabilities of the African nation provided large scope of autonomy to these fledgling multinationals to exploit loopholes in the regulatory framework. They had no locals in the management cadres, freedom of association was allowed but not respected and wages were pegged at the national minimum wage. The authors believed that they are unlikely to improve working conditions unless there were tangible benefits to their businesses.

A study of few privately owned Chinese MNCs in Vietnam by Cooke and Lin (2012) revealed that they experienced tighter labour regulations, more freedom enjoyed by trade unions in negotiations (resulting in more industrial unrest and rising wages) and different work-life values and expectations of Vietnamese employees compared with China. They also felt that the territorial disputes between the two countries adversely affected employee attitudes towards Chinese employers.

A survey of South African firms operating in China found that they considered the following to be the most important considerations to operate successfully in China: understanding the market complexity, important of joint venture partnerships, Guanxi relationship networks, human capital, language and culture, and regulatory environment (Horwitz et al., 2005). They believed that the extent of cultural diversity has equipped South African managers to operate effectively in markets that are culturally dissimilar to them. Supporting this view, Wocke et al. (2007, p. 830) state that the competencies developed by South African firms to manage high degrees of complexity and ambiguity in the domestic market gave them an advantage when operating in different national cultures. Similarly, Thite et al. (2014) found that Indian IT MNCs operating in China faced several structural and cultural challenges in managing the local workforce; for example, the Chinese employees' lack of exposure to services offshoring, poor quality of leadership, Chinese-centric thinking and difficulties in adopting performanceoriented culture. 


\section{DISCUSSION AND CONCLUSIONS}

While established Western multinationals have previously been challenged by the then emerging multinationals from countries such as Japan and Korea, the 'new kids on the block', including from BRICS, are rising rapidly, both organically and via mergers and acquisitions and their key strength lies in their ability to create disruptive business models (Verma et al., 2011). In order to overcome the host of disadvantages arising from the poor perception of the country of their origin, being late-comers, being small and being ill-experienced compared with their established and well-experienced rivals from developed economies, there is an urgent need for these infant multinationals to fill the gaps in their knowledge quickly, and therefore they tend to acquire strategic assets in developed markets to seek intangible resources.

At the same time, they are exploiting their ability to develop products and services suitable for bottom-of-the-pyramid markets coupled with the capability and agility to operate in politically, socially and economically uncertain environments, both at home and similar countries around the world. The EMNCs exude confidence and ambition with some being born-globals and some taking on the established rivals with cutting edge R\&D. Thus, slowly but surely they are transforming themselves from being imitators to innovators (Economist, 2010).

The hunger for natural resources is also driving large and fast growing economies of China and India to the African continent and the Commonwealth of Independent States. They are also entering into Latin America, Central and Eastern Europe to set up near-shore centres to cater to the developed markets. Also, as their own economies grow, which often register double-digit growth, wages and cost of doing business in China and India are also growing, forcing them to enter into low-cost countries, such as Bangladesh, Vietnam and the Philippines. When this scenario is contrasted with the sluggish and ailing economies in the USA and Western Europe, one can clearly see why and how the global economy is undergoing fundamental changes. In describing how this has positively affected the global economy, BCG (2011) notes:

[EMNCs or global challengers] have been the hidden engines of the global economy in recent years. Despite the economic slowdown that closed the past decade, global per capita GDP rose by 50 percent, and 250 million people were lifted out of poverty over the last ten years. Trade is freer now than a decade ago, and global exports have doubled. (BCG, 2011, p. 1) 


\section{Handbook of HRM in emerging markets}

That said, the road ahead is full of challenges for EMNCs. While the booming global economy in the early to mid-2000s acted as a launching pad for the EMNCs, the global financial crisis (GFC) and the current gloomy economic outlook have certainly put the brakes on the rapid growth rate of EMNCs. The depressed economy, high unemployment rates and the attempt by developing economies to take over marquee brands have given rise to political and social hostility in some Western countries and if unchecked can derail the globalization of the world economy. At the same time, established MNCs are fighting back by putting pressure on the governments of their home countries to protect or subsidize them from competition from low-cost countries to continue to operate in home countries and also by revising their business strategies to take on the rising might of the EMNCs, particularly in developing markets.

Maintaining the balance between standardization and localization or the push for control from headquarters and pull for autonomy by subsidiaries is one of the key challenges in the management of multinational corporations (Hillman and Wan, 2005). The experience of MNCs from BRICS, as discussed before, reveals that many of them tend to centralize corporate decision making process, including that of international HR strategy formulation, at the headquarters for fear of losing control. As the EMNCs grow further with increasing share of international revenue as well as foreign workforce, this problem will become more acute. It might be a matter of learning curve or mindset but nevertheless needs to be addressed, especially as EMNCs move from the phase of entering international markets to expansion and consolidation (Fleury and Fleury, 2011).

Managing international human resources does seem to be a weakness rather than strength in most EMNCs from the BRICS block, with the notable exception of Indian multinationals in the IT sector which are mostly born-globals and have leveraged on their HRM excellence from their inception in an industry where intellectual capital is the key ingredient of success (Thite et al., 2014). The challenges in this regard are multifaceted; for example,

- the Brazilian MNCs do not pay enough attention to developing global HR competency (Muritiba et al., 2012);

- Russian MNCs find it challenging to develop an innovation-centric mindset in their workforce and shed local cultural baggage (Filippov, 2012, 2011); 
- Indian MNCs struggle to develop a global leadership pipeline as they currently depend too much on home-grown talent (Thite et al., 2014);

- Chinese MNCs find global talent management to difficult, particularly in economies that are too different than theirs (Teagarden and Cai, 2009); and

- South African MNCs consider workforce capability development and managing employee expectations as some of the key HR challenges (Grzeschke and Moehring, 2004).

Most of these HR challenges are due to EMNCs' lack of experience as global players and one can expect that as they grow, they will learn. What is noticeable is that most studies on EMNCs uniformly stress the realization amongst managers in EMNCs that they have a long way to go and that they need to learn fast. As summed up by a senior manager in an Indian MNC:

the challenges (we face) are ... more evolutionary issues, more globalization issues, more scalability issue(s) ... have I learnt fast enough, that is the bigger challenge. (Thite et al., 2014)

As EMNCs face common challenges in their quest for internationalization and also considering the growth within the emerging economies, there is a need for EMNCs to learn from each other, apart from learning from advanced economies. For example, according to Horwitz (2012),

[there is an] emergent managerial belief in South African firms, that there is much to be learned from Indian, Chinese and Japanese managerial practices, particularly as these might have a higher likelihood of adoption in the African cultural context ... This may, however, be a somewhat normative belief ... (because there are) fundamental differences between them. (Horwitz 2012, p. 2949)

One can also expect cross-learning between EMNCs and established MNCs. For example, while EMNCs learn how to manage their operations in developed economies from established MNCS, the latter will in turn learn how to operate in the developing markets from the former and importantly, this cross-learning will take place on equal footing (Deng, 2012 , p. 325). In the process, they will simultaneously compete and collaborate, which Luo and Rui (2009) call as 'co-opetition', an aspect of ambidexterity perspective. 


\section{Handbook of HRM in emerging markets}

This discussion takes us to the global or corporate roles played by HR in EMNCs. We have already identified the need for EMNCs to learn from their established rivals and from each other in managing global operations which in turn underscores the importance of HR's knowledge management role within MNCs (Sparrow et al., 2003). Thite et al. (2014) have identified other possible corporate HR roles in EMNCs to be strategic business partner, guardian of culture, builder of global workforce and capabilities, champion of processes, and facilitator of employee development. These roles may look similar to the ones found in the literature for all MNCs (Farndale et al., 2010) but their conceptualization, contextualization and implementation would be quite different in the context of EMNCs. The following observations by Cooke (2008), made in the context of Chinese MNCs, seem to hold good for all EMNCs:

Having HR talent at the headquarters of Chinese MNCs who are capable of designing and implementing corporate HR strategy that forms an integral part of their corporate business strategy therefore has a strategic implication for the success of Chinese MNCs. (Cooke, 2008, p. 260)

With regard to convergence or divergence of HR practices in EMNCs, the consensus from the existing literature is that there is a considerable degree of variance. For example,

- The HR strategies in Brazilian technology MNCs were found to be more localized than internationalized (Muritiba et al., 2010).

- Russian MNCs seem to seek convergence based on geographical proximity and cultural-historical closeness in their choice of countries for internationalization (Kuznetsov, 2012).

- Indian MNCs followed an 'adaptive approach' in managing subsidiaries in developed markets and a 'highly localized approach' in developing markets (Thite et al., 2012).

- Cooke (2008, p. 260) hypothesized that 'there is a greater opportunity for the Chinese HR practices to be transferred to their subsidiaries in developing countries than that to developed countries'.

This underscores the need to move away from static distinctions of convergence and divergence between HR practices and move towards cross-vergence models and from descriptive cross-cultural adoption to within cultural variables (Horwitz, 2012; Jackson, 2001, Chatterjee and Pearson, 2001). For example, the literature on HRM in EMNCs seem to support the Afro-Asian nexus proposed by Horwitz (2012) built around 
the traditions of collectivist societies as seen in Brazilian EMNCs (Fleury and Fleury, 2011) and Indian MNCs (Cappelli et al., 2010a and 2010b).

The rapidly increasing number of EMNCs is a relatively recent development with some having less than ten years of growth. As such we know very little about them and what we know is insufficient to draw reliable and valid conclusions. But what is clear is that they are here to stay and grow. Accordingly, we need further research focused on them in all areas of enquiry in all fields of social sciences. Some areas worth exploring in future studies have already been noted in the early sections of this chapter.

In terms of future research directions on HRM in EMNCs, Horwitz (2012) states:

The cultural/institutional complexity of emerging markets precludes oversimplified analysis ... The growth of emerging market MNCs raises the question of contingency approaches and mediating variables affecting organizational level application of HRM practices in difference markets. (Horwitz, 2012, pp. 2940 and 2942)

Also, while there is anecdotal evidence of 'reverse diffusion', as advocated by Edwards (1998), we need further research on whether and how EMNCs transfer the best practices learned from their overseas subsidiaries to home countries and markets (Horwitz, 2012).

In conclusion, if emerging markets are the growth engines of the global economy, the new multinationals from these markets are the spark plugs of these engines, spurring all round growth and innovation. In the global economy of the twenty-first century, characterized by services, knowledge, technology, innovation and globalization, human resource management will remain a key competitive advantage for all firms, domestic and foreign and for all markets, emerging or established.

\section{REFERENCES}

Akorsu, A.D. and Cooke, F.L. (2011), 'Labour standards application among Chinese and Indian firms in Ghana: Typical or atypical?', International Journal of Human Resource Management, 22 (13), 2730-2748.

Barney, J.B., Ketchen, D.J. and Wright, M. (2011), 'The future of resource-based theory: Revitalization or decline?', Journal of Management, 37 (5), 1299-1315.

Bartlett, C.A. and Ghoshal, S. (2000), 'Going global: Lessons from late movers', Harvard Business Review, 78, 133-142.

BCG (2011), The 2011 BCG Global Challengers: Companies on the move. Boston: Boston Consulting Group.

Cappelli, P., Singh, H., Singh, J. and Useem, M. (2010a), 'The India way: Lessons for the US', Academy of Management Perspectives, 24 (2), 6-24. 


\section{Handbook of HRM in emerging markets}

Cappelli, P., Singh, H., Singh, J. and Useem, M. (2010b), 'Leadership lessons from India', Harvard Business Review, March, 90-97.

Chang, Y.Y., Wilkinson, A. and Mellahi, K. (2007), 'HRM strategies and MNCs from emerging economies in the UK', European Business Review, 19 (5), 404-419.

Chatterjee, S.R. and Pearson, A. L. (2001), 'Indian managers in transition: Orientations, work goals, values and ethics', Management International Review, 40 (1), 81-95.

Chen, M.J. and Miller D. (2010), 'West meets East: toward an ambicultural approach to management', Academy of Management Perspectives, 24 (4), 17-24.

Chen, M.J. and Miller D. (2011), 'The relational perspective as a business mindset: Managerial implications for East and West', Academy of Management Perspectives, 25 (3), 6-18.

Contractor, F.J., Kumar, V. and Kundu, S.K. (2007), 'Nature of the relationship between international expansion and performance: The case of emerging market firms', Journal of World Business, 42, 401-417.

Cooke, F.L. (2008), Competition, Strategy and Management in China. New York: Palgrave Macmillan.

Cooke, F.L. and Lin, Z. (2012), 'Chinese firms in Vietnam: Investment motives, institutional environment and human resource challenges', Asia Pacific Journal of Human Resources, 50, 205-226.

Cuervo-Cazurra, A. and Genc, M. (2008), 'Transforming disadvantages into advantages: Developing-country MNEs in the least developed countries', Journal of International Business Studies, 39, 957-979.

Deng, P. (2012), 'Accelerated internationalization by MNCs from emerging economies: Determinants and implications', Organizational Dynamics, 41, 318-326.

Dixon, S.E.A., Meyer, K.E. and Day, M. (2010), 'Stages of organizational transformation in transition economies: A dynamic capabilities approach', Journal of Management Studies, 47 (3), 416-436.

Economist (2010), 'The world turned upside down: a special report on innovation in emerging markets', http://www.economist.com/node/15879369 accessed 27 September 2011.

Edwards, C. and Zhang, M. (2003), 'Human resource management strategy in Chinese MNCs in the UK: A case study with six companies', Research and Practice in Human Resource Management, 11 (1), 1-14.

Edwards, T. (1998), 'Multinationals, labor management and the process of reverse diffusion', International Journal of Human Resource Management, 9 (4), 696-709.

Farndale, E., Paauwe, J., Morris, S., Stahl, G., Stiles, P., Trevor, J. and Wright, P. (2010), 'Context-bound configurations of corporate HR functions in multinational corporations', Human Resource Management, 49 (1), 45-66.

Filippov, S. (2011), 'Innovation and R\&D in emerging Russian multinationals', Economics, Management and Financial Markets, 6 (1), 182-206.

Filippov, S. (2012), 'Emerging Russian multinational companies: Managerial and corporate challenges', European Journal of International Management, 6 (3), 323-341.

Fleury, A. and Fleury, M.T.L. (2011), Brazilian Multinationals. Cambridge: Cambridge University Press.

Gammeltoft, P., Barnard, H. and Madhok, A. (2010), 'Emerging multinationals, emerging theory: Macro-and micro-level perspectives', Journal of International Management, 16, 95-101.

Gerhart, B. and Fang, M. (2005), 'National culture and human resource management: Assumptions and evidence', International Journal of Human Resource Management, 16 (6), 971-986.

Goldstein, A. (2009), Multinational Companies from Emerging Economies. New York: Palgrave Macmillan. 
Goldstein, A. and Prichard, R. (2009), South African multinationals: Building on a unique legacy, in R. Ramamurti and J. Singh (eds), Emerging Multinationals in Emerging Countries. Cambridge: Cambridge University Press, pp. 244-279.

Grzeschke, C. and Moehring, D. (2004), 'Human resource practices in multinational companies in South Africa', MBA thesis, University of Cape Town, Graduate School of Business.

Gullién, M.F. and Garcia-Canal, E. (2009), 'The American model of the multinational firm and the new multinationals from emerging economies', Academy of Management Perspectives, 23 (2), 23-35.

Harzing, A.-W. and Sorge, A. (2003), 'The relative impact of country of origin and universal contingencies in internationalization strategies and corporate control in multinational enterprises: Worldwide and European perspectives', Organization Studies, 24 (2), 187.

Hillman, A. and Wan, W.P. (2005), 'The determinants of MNE subsidiaries' Political Strategies: Evidence of Institutional Duality', Journal of International Business Studies, 36 (3), 322-340.

Hofstede, G. (2007), 'Asian management in the 21st century', Asia Pacific Journal of Management, 24 (4), 411-420.

Horwitz, F.M. (2012), 'Evolving human resource management in Southern African multinational firms: Towards an Afro-Asian nexus', International Journal of Human Resource Management, 23 (14), 2938-2958.

Horwitz, F. M. and Mellahi, K. (2009), 'Human resource management in emerging markets', in D.G. Collings and G. Wood (eds), Human Resource Management: A Critical Approach. London: Routledge, pp. 263-295.

Horwitz, F.M., Ferguson, M., Rivett, I. and Lee, A. (2005), 'An Afro-Asian nexus: South African multinational firm experiences in Chinese labor markets', South African Journal of Business Management, 36 (3), 29-40.

Jackson, T. (2001), 'Cultural values and management ethics: A 10-nation study', Human Relations, 54, 1267-1302.

Jonsson, S. (2008), Indian Multinational Corporations: Low-Cost, High-Tech or Both? Ostersund, Sweden: Swedish Institute for Growth Policy Studies.

Khanna, T. and Palepu, K.G. (2005), Spotting Institutional Voids in Emerging Markets. Boston, MA: Harvard Business School Publishing.

Klien, S. and Wocke, R. (2009), 'Protective incubators and South African MNEs', Thunderbird International Business Review, 51 (4), 341-354.

Kumar, N. (2007), 'Emerging TNCs: trends, patterns and determinants of outward FDI by Indian enterprises', Transnational Corporations, 16 (1), 1-26.

Kuznetsov, A.V. (2012), 'The development of Russian multinational corporations', International Studies of Management \& Organization, 41 (4), 34-50.

Lengnick-Hall, M.L., Lengnick-Hall, C.A., Andrade, L.S. and Drake, B. (2009), 'Strategic human resource management: The evolution of the field', Human Resource Management Review, 19, 64-85.

Luo, Y. and Rui H. (2009), 'An ambidexterity perspective toward multinational enterprises from emerging economies', Academy of Management Perspectives, 23 (4), 49-70.

Luo, Y. and Tung, R.L. (2007), 'International expansion of emerging market enterprises: A springboard perspective', Journal of International Business Studies, 38, 481-498.

Makela, K., Sumelius, J., Hoglund, M. and Ahlvik, C. (2012), 'Determinants of strategic HR capabilities in MNC subsidiaries', Journal of Management Studies, 49 (8), $1459-1483$.

Mathews, J.A. (2006), 'Dragon multinationals: New players in 21st century globalisation', Asia Pacific Journal of Management, 23, 5-27. 


\section{Handbook of HRM in emerging markets}

Matthews, J. and Zander, I. (2007), 'The international entrepreneurial dynamics of accelerated internationalization', Journal of International Business Studies, 38 (3), 387-403.

Minbaeva, D., Pedersen, T., Bjorkman, I., Fey, C.F. and Park, H.J. (2003), 'MNC knowledge transfer, subsidiary absorptive capacity and HRM', Journal of International Business Studies, 34, 586-599.

McCarthy, D.J., Puffer, S. and Vikhanski, O. (2009), 'Russian multinationals: Natural resources champions', in R. Ramamurti and J. Singh (eds), Emerging Multinationals in Emerging Countries. Cambridge: Cambridge University Press, pp. 167-199.

Muritiba, P.M., Muritiba, S.N., Campanario, M. and Albuquerque, L.G. (2010), 'International HR strategy in Brazilian technology multinationals', Brazilian Administration Review, 7 (4), 325-344.

Muritiba, P.M., Muritiba, S.N., Albuquerque, L.G., Fleury, M.T.L. and French, J.L. (2012), 'Challenges for Brazilian MNCs' international human resource management', European Journal of International Management, 6 (3), 248-264.

Narula, R. and Jormanainen, I. (2008), 'When a good science base is not enough to create competitive industries: Lock-in and inertia in Russian systems of innovation', MERITUNU Working Papers 59, Maastricht.

OECD (2006), Emerging Multinationals: Who are They? What do They do? What is Stake? Paris: OECD.

Parmentola, A. (2011), 'Internationalization strategy of new Chinese multinationals: Determinants and evolution', International Journal of Management, 28 (1), 369-395.

Pradhan, J.P. (2007), 'Growth of Indian multinationals in the world economy: Implications for development'. MPRA Paper No. 12360. New Delhi: Institute for Studies in Industrial Development.

Ramamurti, R. (2009), 'What have we learned from emerging-market MNEs?', in R. Ramamurti, R. and J.V. Singh (eds), Emerging Multinationals in Emerging Markets. Cambridge, UK: Cambridge University Press, pp. 399-426.

Ramamurti, R. and Singh, J.V. (2009), 'Indian multinationals: Generic internationalization strategies', in Ramamurti and Singh (eds) Emerging Multinationals from Emerging Markets. Cambridge, UK: Cambridge University Press.

Scullion, H., Collings, D. and Gunnigle, P. (2007), 'International human resource management in the 21st century: Emerging themes and contemporary debates', Human Resource Management Journal, 17 (4), 309-319.

Shen, J., Edwards, V. and Lee, G. (2005), 'Developing an integrative international human resource model: The contribution of Chinese multinational enterprises', Asia Pacific Business Review, 11 (3), 369-388.

Shen, J. and Edwards, V. (2006), International Human Resource Management in Chinese Multinationals. Abingdon, Oxfordshire: Routledge.

Som, A. (2010), 'Emerging human resource practices at Aditya Birla Group', Human Resource Management, 49 (3), 549-566.

Sparrow, P., Harris, H. and Brewster, C. (2003), 'Towards a new model of globalizing HRM'. Paper presented at the 7 th Conference on International Human Resource Management, University of Limerick, Ireland.

Sun, S.L., Peng, M.W., Ren, B. and Yan, D. (2012), 'Comparative ownership advantage framework for cross-border M\&As: The rise of Chinese and Indian MNEs', Journal of World Business 47 (1), 4-16.

Tanure, B., Barcellos, E.P. and Fleury, M.T.L. (2009), 'Psychic distance and the challenges of expatriation from Brazil', International Journal of Human Resource Management, 20 (5), 1039-1055.

Teagarden, M.B. and Cai, D.H. (2009), 'Developmental lessons from China's global companies', Organizational Dynamics, 38 (1), 73-81.

The Times (2011), 'Africa rising', 23 March, 2. 
Thite, M. (2004), Managing People in the New Economy. New Delhi: Response, Sage.

Thite, M. (2012), 'Strategic global human resource management: Case study of an emerging Indian multinational', Human Resource Development International, 15 (1), 239-247.

Thite, M. (2013), 'Ethics and human resource management and development in a global context: Case study of an Indian multinational'. Human Resource Development International, 16 (1), 106-115.

Thite, M. (2014), 'From local to global HRM: Interviews with HR heads in emerging Indian multinationals', International Journal of Indian Culture and Business Management, 9 (2), 151-163.

Thite, M. and Dasgupta, B. (2011), 'Indian multinationals overseas: Tracking their global footprints' in P. Budhwar and V. Varma (eds), Doing Business in India. Abingdon, Oxfordshire: Routledge, pp. 250-265.

Thite, M., Budhwar, P. and Wilkinson, A. (2014), 'Global HR roles and factors influencing their development: Evidence from emerging Indian IT services multinationals', Human Resource Management, 53 (14).

Thite, M., Wilkinson, A. and Shah, D. (2012), 'Internationalization and HRM strategies across subsidiaries in multinational corporations from emerging economies - A conceptual framework', Journal of World Business, 47 (2), 251-258.

Verma, S., Sanghi, K., Michaelis, H., Dupoux, P., Khanna, D. and Peters, P. (2011), The Success of Challengers: 2011 BCG Global Challengers, bcg.perspectives, The Boston Consulting Group.

UNCTAD. (2006), FDI from developing and transition economies: Implications for development, World Investment Report 2006, New York: United Nations Conference on Trade and Development.

UNCTAD (2007), World Investment Report 2007: Transnational Corporations, Extractive Industries and Development. New York: United Nations Conference on Trade and Development.

UNCTAD (2009), World Investment Report 2009: Transnational Corporations, Agricultural production and Development. New York: United Nations Conference on Trade and Development.

UNCTAD (2012), World Investment Report 2012: Towards a new generation of investment policies. New York: United Nations Conference on Trade and Development.

Warner, M. and Nankervis, A. (2012), 'HRM practices in Chinese MNCs; rhetoric and reality', Journal of General Management, 37 (3), 61-80.

Wocke, A., Bendixen, M. and Rijamampianina, R. (2007), 'Building flexibility into multi-national human resource strategy; A study of four South African multi-national enterprises', International Journal of Human Resource Management, 18 (5), 829-844.

Wright, M., Filatotchev, I., Hoskisson, R.E. and Peng, M.W. (2005), 'Guest editors' introduction, strategy research in emerging economies: Challenging the conventional wisdom', Journal of Management Studies, 42 (1), 1-33.

Zheng, C. (2013), 'Critique and extension of strategic international human resource management framework for dragon multinationals', Asia Pacific Business Review, 19 (1), 1-15.

Zheng, C. and Lamond, D. (2009), 'A critical review of human resource management studies (1978-2007) in People's Republic of China', International Journal of Human Resource Management, 20 (11), 2194-2227. 